\title{
Calendrier des activités (de juillet 2008 à juin 2009)
}

\section{(2) OpenEdition}

10 Journals

Édition électronique

URL : https://journals.openedition.org/cem/8272

DOI : $10.4000 /$ cem. 8272

ISSN : 1954-3093

Éditeur

Centre d'études médiévales Saint-Germain d'Auxerre

\section{Édition imprimée}

Date de publication : 15 août 2008

ISSN : 1623-5770

Référence électronique

"Calendrier des activités (de juillet 2008 à juin 2009) », Bulletin du centre d'études médiévales d'Auxerre I BUCEMA [En ligne], 12 | 2008, mis en ligne le 15 septembre 2009, consulté le 22 septembre 2022.

URL : http://journals.openedition.org/cem/8272 ; DOI : https://doi.org/10.4000/cem.8272

Ce document a été généré automatiquement le 22 septembre 2022.

\section{(c) (i) (2)(2)}

Creative Commons - Attribution - Pas d'Utilisation Commerciale - Partage dans les Mêmes Conditions 4.0 International - CC BY-NC-SA 4.0

https://creativecommons.org/licenses/by-nc-sa/4.0/ 


\section{Calendrier des activités (de juillet 2008 à juin 2009)}

1 Année 2008

\begin{tabular}{|l|l|}
\hline 30 juin-4 juillet & $\begin{array}{l}\text { Tours - Proportions. Arts, architecture, musique, mathématiques et sciences, Vasco } \\
\text { ZARA }\end{array}$ \\
\hline 4-5 septembre & $\begin{array}{l}\text { Tonnerre - Espaces, objets et populations dans les établissements hospitaliers du } \\
\text { Moyen Âge au XX } \text { siècle, Sylvie LE CLECH }\end{array}$ \\
\hline $\begin{array}{l}\text { 25-26 } \\
\text { septembre }\end{array}$ & $\begin{array}{l}\text { Auxerre - L'Arc triomphal dans l'espace ecclésial. De l'Antiquité au Moyen Age central } \\
\text { en Occident, Caroline Roux }\end{array}$ \\
\hline 3-4 octobre & Auxerre - Exégèse et prédication (IX'-XII siècle), SUmi SHIMAHARA et João GOMES \\
\hline 6-10 octobre & Auxerre - Workshop Les toits de l'Europe, Sylvain AUMARD \\
\hline 8-10 octobre & $\begin{array}{l}\text { Paris et Auxerre - Charlemagne et les objets. Des thésaurisations carolingiennes aux } \\
\text { constructions mémorielles, Marianne BESSEYRE et Philippe CORDEZ }\end{array}$ \\
\hline \hline 16-17 octobre & Dijon - Autour du « Puits de Moïe ". Pour une nouvelle approche, Daniel RUSSO \\
\hline \hline 17-18 octobre & Auxerre - Texts and Identities in the Early Middle Ages, Régine LE JAN \\
\hline
\end{tabular}

2 Année 2009

\begin{tabular}{|l|l|}
\hline 23 janvier & $\begin{array}{l}\text { Dijon - CBMA. Chartae Burgundiae Medii Aevi III. Systèmes d'interrogation et } \\
\text { recherches sur les fonds diplomatiques bourguignons, Marie-José GASSE-GRANDJEAN et } \\
\text { Eliana MAGNANI }\end{array}$ \\
\hline
\end{tabular}


Avril (dates à Auxerre - Stage d'archéologie du bâti (2 semaines) : sous-sol du temple de l'église préciser) réformée, ancienne église Saint-Pèlerin

17-19 juin Auxerre - Figures des musiciens II. Les inventions de la musique au Moyen Âge, Martine CLOUZOT et Eduardo Henrik AUBERT

Contact : cnrs.cem@wanadoo.fr 